\title{
A scale to assess activities of daily living in persons affected by leprosy
}

\author{
W. H. VAN BRAKEL*, A. M. ANDERSON*, \\ F. C. WÖRPEL*, R. SAIJU*, H. B. BK*, S. SHERPA*, \\ S. K. SUNWAR*, J. GURUNG*, M. DE BOER** \& \\ E. SCHOLTEN** \\ * INF RELEASE Project, Pokhara, Nepal \\ ** University of Groningen Medical School, Groningen, \\ The Netherlands
}

Accepted for publication 4 August 1999

\begin{abstract}
Summary The aim of this study was to develop a scale for identifying disability among people in the rural areas of developing countries. The studies were carried out in the Green Pastures Hospital and the leprosy field programme of the Western Region of Nepal. With the help of staff experienced in working with people with disability, a 68-question questionnaire was made, based on the International Classification of Impairments, Activities and Participation (ICIDH-2). A survey was carried out of 269 people affected by leprosy who had impairments, as well as a sample of those who were unimpaired. The survey results were used to develop the questionnaire into a scale, using standard scale development methods. This included checking of criterion validity, discrimination and reliability and stability using weighted kappa statistics. Of the 68 questions, 38 were included in the second draft of the instrument. Eight questions were added to identify difficulty in relationships, about the use of aids and about occupation and employment. The sum score of the scale against the expert score gave a Spearman correlation coefficient of 0.72 . Intra- and inter-interviewer reliability coefficients were 0.77 (95\% CI $0.73-0.81)$ and 0.61 (95\% CI $0.56-0.67)$, respectively. The stability test gave an overall kappa of $0 \cdot 76(95 \%$ CI $0 \cdot 70-0 \cdot 82)$. Four questions with particularly poor results were omitted from the final draft of the instrument. An interview-based instrument was developed for identifying limitations in activities of daily living (disability) in people living in a rural setting in a developing country-the Green Pastures Activity Scale (GPAS). The scale performed well during validity and reliability testing. It consists of 34 activity questions, five relationship questions, and three questions on the use of aids, occupation and employment.
\end{abstract}

\section{Introduction}

Leprosy often causes impairment of autonomic, sensory and motor nerve function. ${ }^{1-3}$ This in

Correspondence to: Dr W. H. van Brakel, c/o TLM Nepal, PO Box 151, Kathmandu, Nepal. e-mail: wvbrakel@iname.com 
turn leads to secondary impairments or deformities of the eyes, face, hands and feet. ${ }^{4,5}$ Too often these become irreversible before the affected person receives appropriate treatment. Impairments and deformities (visible impairments) may cause limitation of activities of daily living (disability) and adverse social reactions (restriction of participation).

The International Classification of Impairments, Activities and Participation (ICIDH-2): ${ }^{6}$ defined impairment as 'a loss or abnormality of body structure or of a physiological or psychological function, e.g. loss of a limb, loss of vision'.

Activity is defined as 'the nature and extent of functioning at the level of the person, e.g. taking care of oneself, maintaining a job' In the field of rehabilitation, limitation of activities is commonly called 'disability'.

Participation is 'the nature and extent of a person's involvement in life situations in relation to Impairment, Activities, Health Conditions and Contextual Factors, e.g. participation in community activities, obtaining a driving license'. Restriction in participation was called 'handicap' in the first edition of the ICIDH.

As a result of fixed-duration multidrug therapy (MDT), the number of leprosy cases on treatment has decreased considerably in recent years. ${ }^{7}$ Thus, attention is shifting to the needs of those 'cured' with MDT, but left with residual impairments, activity limitation or participation restrictions. ${ }^{8}$ These cause long-term problems for the individual and place a demand on community resources. The global number of people with irreversible deformities due to leprosy is estimated to be between 1 and 2 million-up to twice the number of cases currently registered for MDT. ${ }^{9}$

Aware of the rehabilitation needs of people affected by leprosy, several authors have pointed out the advantages of applying the ICIDH concepts in leprosy. ${ }^{8,10-12}$ The first edition of the ICIDH, published by the WHO in 1980, has been succeeded by the second edition, the ICIDH-2. ${ }^{6}$ It is important that the outcome of rehabilitation be assessed in terms of disability and handicap. ${ }^{13}$ The concepts described in the $\operatorname{ICIDH}(-2)$ may help in this.

Information on the impairment and activity status of people affected by leprosy may be used for: (i) decision making and management concerning (physical) rehabilitation of individual patients, (ii) assessing the effectiveness of a leprosy programme in preventing the development of (further) impairments and activity limitations, and treatment of preexisting ones, and (iii) planning of resources needed for treatment and care of patients with impairments and activity limitations, before and after release from drug therapy.

No 'instrument' has been developed for identifying limitation in activities of daily living (ADL) suitable for use with people affected by leprosy in developing countries. Many disability scales are available in Western countries, ${ }^{14-18}$ but none appeared suitable for use with people living under conditions common in rural areas of leprosy-endemic countries.

With increasing emphasis on rehabilitation, such a tool is needed to assess adequately the rehabilitation needs of those affected by leprosy and to evaluate the results of rehabilitation interventions. Using standard scale development techniques, we designed such an instrument: the Green Pastures Activity Scale (GPAS). This paper describes the development of the GPAS.

\section{Materials and methods}

The studies were carried out in the Green Pastures Hospital of the International Nepal Fellowship in Pokhara and in the leprosy field programme of the Western Region of Nepal. 
STEPS IN THE SCALE DEVELOPMENT PROCESS

Standard procedures for scale development were used. ${ }^{19}$ First, suggestions for activities of daily living to be included in the assessment were collected during a group consultation of Nepali staff members experienced in working with people with leprosy, or who had had leprosy themselves. Second, a questionnaire was drawn up in English, translated into Nepali and back translated to check the translation. The third step was pilot testing of the questionnaire on 26 subjects. Questions answered affirmatively (endorsed) less than 10\% of the time or more than $90 \%$ were omitted. The remaining questionnaire was checked for face validity. Extensive validity and reliability testing was not done at this stage, because this instrument was only a precursor of the eventual activity assessment.

Fourthly, using this questionnaire, 269 people affected by leprosy who had impairments and a sample of unimpaired patients were surveyed. All subjects were interviewed about their common daily activities. As far as possible, the interview was conducted in the person's vernacular language, with interviewers of the same sex as the interviewees. They were asked to rank a list of activities on a scale of difficulty of performing them (never do this, same as before, some difficulty, much difficulty, only possible with help or impossible).

In the scale development process, the results of the survey were used for the fifth step. Questions with an endorsement of more than $20 \%$ on the 'don't do' category and questions where fewer than 15 people reported 'much difficulty' (or worse) with the activity were excluded. The remaining questions and a few additional ones, each with a five-point response scale, were rearranged into a new questionnaire, the first draft of our eventual scale. Using the method of Laman and Lankhorst, ${ }^{20}$ an attempt was made to include an additional question for each activity to assess the perceived importance of that activity to the person concerned. The resulting questionnaire was again translated and back-translated to check the understanding of the wording.

The sixth step was the running of a series of pilot studies to check the criterion validity, discrimination, intra- and inter-interviewer reliability and stability of the draft scale. Criterion validity was checked by comparing the sum score of the scale with a sum of scores given by a panel of experienced staff in a sample of 37 patients. Using three groups of people with different severity of impairment, divided according to the 'maximum WHO disability grade method', ${ }^{21}$ we checked the discriminative ability of the scale. Intra- and inter-interviewer reliability was assessed with paired interviews on 29 patients. Four different interviewers were involved. Stability over a period of a week was evaluated in a similar way.

The remaining steps in the GPAS development are checking for responsiveness to change and determining the optimal scoring and summary method.

\section{STATISTICAL METHODS}

The percentage 'endorsement' was used to quantify how many respondents gave a positive answer to a given question, or who indicated that they didn't do that particular activity. ${ }^{19}$ Criterion validity between the sum scores of the draft scale and the expert score was quantified using the non-parametric Spearman rank correlation coefficient. ${ }^{22}$ The chancecorrected percentage of agreement between occasions (intra-tester reliability and stability) and interviewers (inter-tester reliability) was calculated using Cohen's weighted kappa statistic $\left(j_{w}\right)$ for categorical scales. ${ }^{23}$ Kappa values are given with their $95 \%$ confidence intervals. The kappa value ranges from 0 (agreement no better than by chance alone) to 1 
(perfect agreement). Values of $0 \cdot 40$ or less may be interpreted as poor agreement, $0 \cdot 41-0 \cdot 60$ as 'moderate', $0.61-0.80$ as 'good' and values above 0.80 as very good agreement. ${ }^{24}$ The percentage direct agreement between occasions or interviewers is also given. The significance of the difference between two kappa values was tested with an appropriate z-test. ${ }^{23}$

\section{Results}

The group consultation resulted in a long list of possible activities to be questioned. After eliminating activities that were not common enough to be of use in an assessment instrument, a pilot questionnaire with 95 items was drawn up. The endorsement pilot study led to elimination of 24 items, leaving a survey questionnaire consisting of 68 questions (with three additional questions specific for men or women). These questions were based on the Activity domain of the ICIDH-2. The survey showed that severe limitation of activity was not uncommon among people affected by leprosy who had at least some clinically detectable impairment. The detailed results of this survey have been reported elsewhere. ${ }^{25}$

The results of the survey were used to refine the questionnaire further for validity and reliability testing as described under Materials and methods. Of the original 68 questions, 38 were included in pilot- 2 draft of the instrument. Five questions were added to identify difficulty in relationships, one question about the use of aids and two about occupation and employment. These eight questions were added to collect relevant information, but were not intended to be part of the actual scale.

Figure 1 shows the correlation between the sum score of the activity scale and the expert sum score. The Spearman correlation coefficient was 0.72 . Discrimination testing showed significant differences in GPAS sum score between people with WHO impairment grade 0 (no impairment) and grade 2 (visible deformity; results not shown). Table 1 shows the results of the reliability testing. Intra-interviewer reliability was good. The overall kappa for all questions pooled together was $0 \cdot 77$ (95\% CI 0.73-0.81). The percentage direct agreement was $95.5 \%$. As expected, inter-interviewer reliability was less good, with an overall kappa value

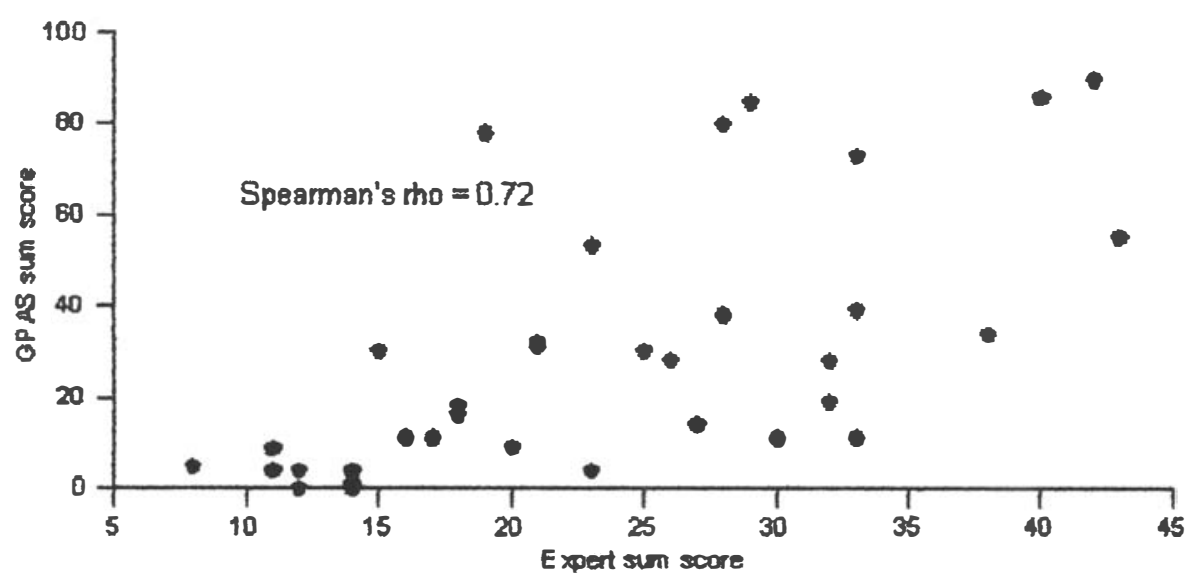

Figure 1. Correlation between the sum score of the Green Pastures Activity Scale and the expert sum score. 
Table 1. Results of reliability testing of the pilot-2 draft of the Green Pastures Activity Scale

\begin{tabular}{|c|c|c|c|c|c|c|c|c|}
\hline & \multicolumn{4}{|c|}{ Difficulty questions } & \multicolumn{4}{|c|}{ Importance questions } \\
\hline & $n^{\mathrm{a}}$ & $k_{w}$ & $95 \% \mathrm{CI}^{\mathrm{b}}$ & $\% \mathrm{DA}^{\mathrm{c}}$ & $n$ & $k_{w}$ & $95 \% \mathrm{CI}$ & $\% \mathrm{DA}$ \\
\hline Intra-tester agreement & 1199 & $0 \cdot 84$ & $0 \cdot 73-0 \cdot 81$ & $95 \cdot 9$ & 877 & $0 \cdot 60$ & $0.53-0.67$ & $93 \cdot 1$ \\
\hline Inter-tester agreement & 1235 & 0.61 & $0 \cdot 56-0.67$ & $92 \cdot 7$ & 918 & $0 \cdot 36$ & $0 \cdot 30-0 \cdot 42$ & 85 \\
\hline Stability & 1061 & 0.76 & $0 \cdot 70-0 \cdot 82$ & $95 \cdot 6$ & 792 & 0.66 & $0.59-0.73$ & $91 \cdot 6$ \\
\hline
\end{tabular}

$k_{w}=$ weighted kappa, ${ }^{\mathrm{a}} n=$ total number of questions included in the calculations, ${ }^{\mathrm{b}} 95 \%$ confidence interval for $k_{w}$, c percentage direct agreement.

of 0.61 (95\% CI $0 \cdot 56-0 \cdot 67)$. Direct agreement was still $92 \cdot 7 \%$. The stability test resulted in an overall kappa of $0 \cdot 76$ (95\% CI $0 \cdot 70-0 \cdot 82$ ), with direct agreement in $95.6 \%$ of questions.

The results were also analysed by interviewer, by question and by interviewee. One interviewer appeared to do less well than the others, with significant differences between the overall kappa values (data not shown). Four questions that gave particularly poor results (weighted kappa $<0 \cdot 40$ ) were omitted from the final draft of the instrument.

The results of the reliability testing were much poorer for the 'importance questions' than for the 'difficulty questions' (see Table 1). Feedback from the interviewers suggested that many interviewees had difficulty understanding the concept of asking 'How important is it to you to ...?' During the drafting and translating of the questionnaire, this problem had already been encountered. We tried rephrasing these questions and put the least misunderstood version in the pilot- 2 scale. However, after reviewing the results of the reliability testing, we decided to omit these questions altogether, thereby shortening the questionnaire considerably.

The final draft of the instrument was named the 'Green Pastures Activity Scale' (GPAS). The English translation of the scale is shown in the Appendix.

\section{Discussion}

Irreversible impairments and deformities are the main causes of the complex of negative social reactions attached to leprosy, commonly known as 'stigma'. ${ }^{26,27}$ Many investigators have studied the types of impairment occurring in leprosy and their prevalence, often using the term 'disabilities, ${ }^{28-31}$ Others have described the management of impairments ${ }^{4,5,32}$ and their incidence and associated risk factors. ${ }^{33-36}$ However, few studies have addressed disability (activity limitation) as defined in the ICIDH. ${ }^{6}$

People with impaired sensation of the hands, weakness of muscles and deformities of hands and feet may have difficulty with many activities. However, in case management leprosy workers of ten do not consider the difficulties people experience in activities of daily life. Reconstructive surgery of hands, feet and face, in an attempt to replace lost muscle function, dates back to the pioneering work of Dr Paul Brand and others, more than 4 decades ago. ${ }^{37,38}$ Nevertheless, a holistic approach to rehabilitation, including physical, psychological, spiritual and socioeconomic aspects, has been lacking.

In assessing the outcome of treatment or rehabilitation, measures of activity (disability) and social participation (handicap) are much more meaningful for the person involved and thus for clinical decision making. ${ }^{39,40}$ However, ADL and participation (handicap) scales 
used in Western countries are not appropriate to identify the problems experienced by people living in developing countries, particularly not those of people living in rural areas. We developed the Green Pastures Activity Scale (GPAS) in an attempt to provide a tool suited to this task, especially for use with people affected by leprosy. The GPAS is an interview-based instrument to identify difficulty experienced in activities of daily living. This will potentially allow the instrument to be used under field conditions as well as in referral centres. The structure of the scale is based on the 'Activity' concept of the ICIDH-2. Validity, discrimination and reliability testing in a series of pilot studies showed very acceptable results.

We included questions about perceived importance of the various activities in the questionnaire to subjectively weight reported disability. ${ }^{20}$ However, the pilot testing showed that such questions were not sufficiently well understood to be reliable. They were therefore omitted from the final scale. Although interviewers were instructed in interview techniques for the GPAS, inter-interviewer reliability can perhaps be further improved through additional training. Responsiveness to change and the best way to summarize the scale into a single index are still under investigation. The GPAS will be made available for general use. An English copy of the scale and instructions for its use can be obtained from the corresponding author.

\section{AN EXAMPLE}

Mr S. is a 27-year-old self-employed tailor referred to the clinic for rehabilitation. He has extensive impairments on both hands: complete bilateral ulnar/median palmar anaesthesia and motor paralysis with mobile clawing of four fingers on his right hand. He also has a partial footdrop on the left. All impairments are over 3 years old. He has completed 24 months of MDT, but says he is unable to do his job, because he cannot thread or hold a needle anymore. The GPAS interview identified severe difficulty with mobility, because he lives in a hillside village and cannot lift his foot high enough when walking uphill. In addition, he reported severe limitations with activities requiring fine dexterity, scoring 'very difficult' on items like opening containers or bottles (13), cutting nails (24), using buttons, hooks or pins (28) or making knots (29).

He underwent surgical correction of his footdrop and claw hand, which resolved the walking limitation, but not the dexterity problem. Therefore, at his request, weaving training was arranged, followed by a micro-credit loan to buy a hand loom. This proved successful, as weaving requires less fine dexterity than tailoring.

Use of the GPAS forced the staff to take time to talk with Mr S. and to listen carefully to the difficulties he experienced, as opposed to what they assumed he might have, based on his impairments. They were then able to identify specific areas of activity limitation and offer problem-oriented interventions to help him reintegrate as a contributing member of his community.

\section{CONCLUSIONS}

An instrument was developed for identifying activity limitations in people living in rural areas of a developing country-the Green Pastures Activity Scale. The scale performed well during validity and reliability testing. The GPAS consists of 34 activity questions; in addition, five questions explore difficulty in relationships and three questions the use of aids, occupation and employment status. 


\section{Acknowledgements}

We wish to thank Allart Nugteren, Jasha Fiselier, Helen Price, Sabreena Mahroof, Liz Fuller, Mark Jones, Clair Broadley and Paul Wright for their valuable help with this study. Special thanks go to our mobile team staff, to Dr Frauke Wörpel, former Superintendent and Dr Jukka Knuuttila, Senior Medical Officer at the Green Pastures Hospital, and to the staff of the physiotherapy and occupational therapy departments at GPH for their help in bringing this study to a successful end. May the work at Green Pastures Hospital bring glory to God!

\section{References}

${ }^{1}$ Dastur DK. Pathology and pathogenesis of predilective sites of nerve damage in leprous neuritis. Nerves in the arm and the face. Neurosurg Rev, 1983; 6: 139-152.

2 Job CK. Nerve damage in leprosy. Int J Lepr, 1989; 57: 532-539.

3 van Brakel WH, Khawas IB. Nerve damage in leprosy: an epidemiological study of 396 patients in West Nepal-part 1: definitions, methods and frequencies. Lepr Rev, 1994; 65: 204-221.

${ }^{4}$ ILEP. Prevention of disability. Guidelines for leprosy control programmes. London: ILEP, 1993.

5 Watson JM. Preventing disability in leprosy patients. London: The Leprosy Mission International, 1986.

6 ICIDH-2: International Classification of Impairments, Activities, and Participation. A Manual of Dimensions of Disablement and Functioning. Beta-1 draft for field trials. Geneva: World Health Organization, 1997.

7 World Health Organisation. Global case detection trend in leprosy. Weekly Epidemiol Rec, 1997; 72: 173-180.

8 Palande DD. Nerve involvement in leprosy-prevention and management of deformities:need for a paradigmshift. Lepr Rev, 1994; 65: 161-164.

9 World Health Organisation. Leprosy disabilities: magnitude of the problem. Weekly Epidemiol Rec, 1995; 70: 269-276.

10 Srinivasan H. To control leprosy as if the patient mattered. Ind J Lepr, 1984; 56: 386-395.

11 Brandsma JW, Heerkens YF, Lakerveld-Heyl K, van Ravensberg CD. The international classification of impairments, disabilities and handicaps in leprosy-control projects. Lepr Rev, 1992; 63: 337-344.

12 Smith WCS. The epidemiology of disability in leprosy including risk factors. Lepr Rev, 1992; 63: Supplement $23 \mathrm{~s}-30 \mathrm{~s}$.

13 van Bennekom CAM, Jelles F, Lankhorst GJ. Rehabilitation Activities Profile: the ICIDH as a framework for a problem-oriented assessment method in rehabilitation medicine. Disabil Rehabil, 1995; 17: 169-175.

14 McDowell I, Newell C. Measuring health: a guide to rating scales and questionnaires. New York: Oxford University Press, 1987.

15 Jiwa-Boerrigter H, Van Engelen HGM, Lankhorst GJ. Application of the ICIDH in rehabilitation medicine. Int Disabil Studies, 1990; 12: 17-19.

16 Keith RA, Granger CV, Hamilton BB, Sherwin FS. The functional independence measure: a new tool for rehabilitation. Adv Clin Rehabil, 1987; 1: 6-18.

17 Mahoney FJ, Barthel DW. Functional evaluation: the Barthel index. Md State Med J, 1965; 14: 61-65.

18 Salèn BA, Spangfort EV, Nygren ÅL, Nordemar R. The disability rating index: an instrument for the assessment of disability in clinical settings. J Clin Epidemiol, 1994; 47: 1423-1434.

19 Streiner DL, Norman GR. Health measurement scales. A practical guide to their development and use. Oxford: Oxford University Press, 1989.

${ }^{20}$ Laman H, Lankhorst GJ. Subjective weighting of disability: an approach to quality of life assessment in rehabilitation. Disab Rehabil, 1994; 16: 198-204.

21 WHO Expert Committee on Leprosy. Sixth Report. 768. 1988. Geneva: WHO Technical Report Series.

22 Kirkwood BR. Essentials of medical statistics. Oxford: Blackwell Scientific Publications, 1988.

${ }^{23}$ Cohen J. Weighted kappa:nominal scale agreement with provision for scaled disagreement or partial credit. Psychol Bull, 1968; 70: 213-220.

24 van Brakel WH, van LM, Kets M, Drever W, Khawas IB, Gurung KS. Intra- and inter- tester reliability of sensibility testing in leprosy. Int J Lepr, 1996; 64: 287-298.

25 van Brakel WH, Anderson AMA. Impairment and disability in leprosy: in search of the missing link. Ind J Lepr, 1997; 69: 361-376.

26 Jopling WH. Leprosy stigma [editorial]. Lepr Rev ,1991; 62: 1-12.

27 Frist T. 'Don't treat me like I have leprosy!'. London: TALMILEP, 1996.

${ }^{28}$ Hasan S. A survey of leprosy deformities among the patients of Hyderabad city. Lepr Ind, 1977; 49: 393-399.

29 Kushwah SS, Govila AK, Kushwah J. An epidemiological study of disabilities among leprosy patients attending leprosy clinic in Gwalior. Lepr Ind, 1981; 53: 240-247. 
${ }^{30}$ Girdhar M, Arora SK, Mohan L, Mukhija RD. Pattern of leprosy disabilities in Gorakhpur (Uttar Pradesh). Ind J Lepr, 1989; 61:503-513.

31 Schipper A, Lubbers WJ, Hogeweg M, de Soldenhoff R. Disabilities of hands,feet and eyes in newly diagnosed leprosy patients in eastern Nepal. Lepr Rev, 1994; 65: 239-247.

32 Srinivasan H. Prevention of disabilities in patients with leprosy. A practical guide. Geneva: World Health Organisation, 1993;

${ }^{33}$ Radhakrishna S, Nair GK. Association between regularity in dapsone (DDS) treatment and development of deformity. Int J Lepr, 1987; 55: 425-434.

34 Pönnighaus JM, Boerrigter G. Are 18 doses of WHO/MDT sufficient for multibacillary leprosy; results of a trial in Malawi. Int J Lepr, 1995; 63: 1-7.

35 Richardus JH, Finlay KM, Croft RP, Smith WCS. Nerve function impairment in leprosy at diagnosis and at completion of MDT: a retrospective cohort study of 786 patients in Bangladesh. Lepr Rev, 1996; 67: 297-305.

${ }^{36}$ Reed NK, van Brakel WH, Reed DS. Progress of impairment scores following the commencement of chemotherapy in MB leprosy patients. Int J Lepr, 1997; 65: 328-336.

37 Brand PW. The reconstruction of the hand in leprosy. Ann R Coll Eng, 1952; 11: 350-361.

38 Brand PW, Thomas RE. The place of physical medicine and orthopaedic surgery in leprosy. An investigation into paralysis patterns in the forearm and hand in leprosy. Physiotherapy and neural involvement in leprosy. Suggestions for treatment by physical methods in neural leprosy. Lepr Rev, 1954; 25: 5-41.

39 van Gijn J. Measurement of outcome in stroke prevention trials. Cerebrovasc Dis, 1992; 2: 23-34.

40 Molenaar DSM, de Haan R, Vermeulen M. Impairment,disability,or handicap in peripheral neuropathy: analysis in the use of outcome measures in clinical trials in patients with peripheral neuropathies. $J$ Neurol Neurosurg Psychiatry, 1995; 59: 165-169. 
Appendix

Green Pastures Activity Scale

Name of the patient:

Card number:

Reason for assessment: Admission/Discharge/Home visit/Other:

Something

I can't do

Question

Something I Not A bit Very

because

have to do difficult difficult difficult of the disease

\section{A. Walking}

1. For you, walking outside the house is

2. For you, climbing stairs is

3. For you, walking uphill is

4. For you, walking downhill is

B. Sitting and getting up

5. For you, squatting is

6. For you, sitting with crossed legs is

7. For you, getting up is

C. Seeing

8. For you, recognizing people from far away is

9. For you, seeing small things at a short distance (e.g. reading or putting a thread through a needle) is

D. Preparing meals

10. For you, cutting vegetables is

11. For you, putting pots on the stove is

12. For you, stirring food is

13. For you, opening containers or bottles is

E. Activities in the house

14. For you, sweeping is

15. For you, opening a door is

F. Activities around the house or in the fields

16. For you, opening a tap is

17. For you, cutting grass or rice with an asi is

18. For you, weeding grass or rice is

19. For you, planting seedlings is

26. For you, going to the toilet is

27 . For you, cleaning yourself after toilet is

H. Dressing

28. For you, using buttons, hooks or pins is

29. For you making knots or tying laces (or bows) is

30. For you, putting on shoes or sandals is

31. For you, putting on clothes is

I. Eating and drinking

32. For you, eating with the hand is

33. For you, drinking water from a container or glass is

34. For you, peeling fruit is 


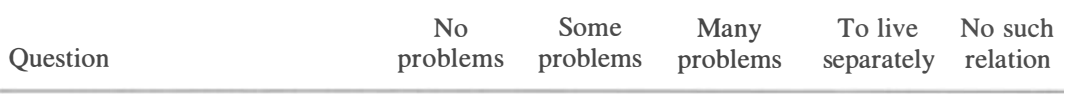

\section{J. Relations}

35. Because of leprosy, in the relationship with your spouse, do you have

36. Because of leprosy, in the relationship with your children, do you have

37. Because of leprosy, in the relationship with your family, do you have

38. Because of leprosy, in the relationship with your neighbours, do you have

39. Because of leprosy, in formal relationship (eg. employer or village head), do you have

\begin{tabular}{lcccc}
\hline & Not & Not & & Very \\
Question & necessary & difficult & Difficult & difficult \\
\hline
\end{tabular}

K. Assistive devices: Do you use (an) assistive device(s)? YES/NO

If yes, which:

40. For you, the use of a device(s) is

L. Occupation: Do you have any difficulty in your job/daily work? YES/NO

41. What is your occupation?

42. Do you do it/daily/sometimes/rainy season/winter season/unemployed? 